\title{
Detection of measles virus genome in bronchoalveolar lavage cells in a patient with measles pneumonia
}

\author{
A. Shimizu*, O. Tanabe*,**, C. Anzai*, K. Uchida*,**, H. Tada*,**, K. Yoshimura*,**
}

\begin{abstract}
Detection of measles virus genome in bronchoalveolar lavage cells in a patient with measles pneumonia. A. Shimizu, O. Tanabe, C. Anzai, K. Uchida, H. Tada, K. Yoshimura. (C) ERS Journals Ltd 2000.

ABSTRACT: Measles is frequently complicated with pneumonia that could be fatal in numerous occasions. However, a prompt and precise diagnosis of measles is not easily made particularly in the early stage of the disease, or in immunocompromised individuals because of the lack of typical clinical features or the defect in antigen-specific antibody production. In the present paper, we describe a 27 -yr-old male who developed fever, skin rash typical of measles, and diffuse pulmonary infiltrates associated with respiratory failure. Infection of lung cells with measles virus was proved by detection of viral genome ribonucleic acid within alveolar macrophages and lymphocytes recovered by bronchoalveolar lavage using reverse transcription-polymerase chain reaction amplification. These techniques may offer a useful tool to make the swift and precise diagnosis of measles pneumonia, thus allowing appropriate therapeutic approaches to the disease.

Eur Respir J 2000; 15: 619-622.
\end{abstract}

Depts of *Gene Therapy, Institute of DNA Medicine, and **Pulmonary and Infectious Diseases, The Jikei University School of Medicine, Tokyo, Japan

Correspondence: K. Yoshimura, Dept of Gene Therapy, Institute of DNA Medicine, The Jikei University School of Medicine, 3-25-8 Nishi-shinbashi, Minato-ku, Tokyo 105, Japan, Fax: 81334331230

Keywords: Bronchoalveolar lavage, detection of measles viral genome, measles pneumonia, reverse transcription-polymerase chain reaction amplification

Received: September 101998

Accepted after revision September 301999

This research was supported in part by a grant from the-Ministry of Education, Science and Culture of Japan.
Measles remains a common infectious disease all over the world, despite the availability of effective vaccines [1]. Most measles-associated deaths result from respiratory tract involvement or neurological complications [2]. Pneumonia is one of the well-known complications of measles infection, and once it occurs, it is serious and often life-threatening [3, 4]. However, recent reports have shown successful treatment of the disease when the appropriate diagnostic approach has been made promptly $[5,6]$. Although the diagnosis of measles pneumonia is based on serum viral titre or immuno-histochemical staining of viral proteins in the lung biopsy specimen, these tests require time-consuming analysis [7]. In patients with serious pneumonia, the prompt diagnosis and immediate treatment are of extreme importance. In this report, we present a 27-yr-old male patient who developed acute respiratory failure caused by measles pneumonia, and describe a rapid and sensitive diagnostic procedure using reverse transcription (RT)-polymerase chain reaction (PCR) amplification detection of the viral ribonucleic acid (RNA) genome in lung cells recovered by bronchoalveolar lavage (BAL).

\section{Case report}

A 27-yr-old, otherwise healthy Japanese male presented with a 3-day history of a nonproductive cough, fever, and a maculopapular skin rash that began from face and progressed to extremities. A viral infection was suspected, and he was treated with an antifebrile. However, increasing weakness developed over the next 2 days that required hospitalization. He had not been previously immunized with the measles vaccine before.

Physical examination on hospital admission revealed a toxic-appearing man with a temperature of $39.6^{\circ} \mathrm{C}$, pulse rate of 94 beats. $\mathrm{min}^{-1}$, arterial blood pressure of 132/78 $\mathrm{mmHg}$, and respiratory rate of 18 breaths $\cdot \mathrm{min}^{-1}$. There were no Koplick spots noted. His neck lymph nodes were enlarged up to $10 \times 10 \mathrm{~mm}$ in size. The lungs were clear as evidenced by auscultation.

Laboratory studies on admission revealed a haemoglobin value of $17.9 \mathrm{~g} \cdot \mathrm{dL}^{-1}$, a platelet count of 122,000 cells. $\mathrm{mm}^{-3}$, and a white blood cell count of 10,300 cells $\cdot \mathrm{mm}^{-3}$ with $93 \%$ neutrophils and 3\% lymphocytes. The CD4+ cell count in peripheral blood on day 4 was 460 cells $\cdot \mathrm{mm}^{-3}$. Serological tests showed a serum immunoglobulin (Ig)G level of $1,170 \mathrm{mg} \cdot \mathrm{dL}^{-1}$, IgM of $168 \mathrm{mg} \cdot \mathrm{dL}^{-1}$, and IgA of $126 \mathrm{mg} \cdot \mathrm{dL}^{-1}$. Chest radiography on admission showed almost "normal" lung.

Two days after admission, the patient complained of progressive exertional dyspnoea. Room-air blood gases revealed arterial oxygen tension $\left(\mathrm{Pa}_{\mathrm{a}} \mathrm{O}_{2}\right)$ of $59 \mathrm{mmHg}$, arterial carbon dioxide tension $\left(\mathrm{Pa}_{\mathrm{a}} \mathrm{CO}_{2}\right)$ of $32 \mathrm{mmHg}$, and $\mathrm{pH}$ of 7.46. A chest radiograph showed diffuse reticulonodular infiltrates of bilateral lungs (fig. 1a). Chest computed tomography (CT) scan revealed diffuse ground-glass opacities, multiple centrilobular nodules, and consolidations predominant in the upper lobe of the right lung (fig. 1b). Specimens recovered by bronchoalveolar lavage (BAL) had increased cellularity with relative increases in lymphocytes $(46 \%)$ and neutrophils $(8 \%)$. 
a)

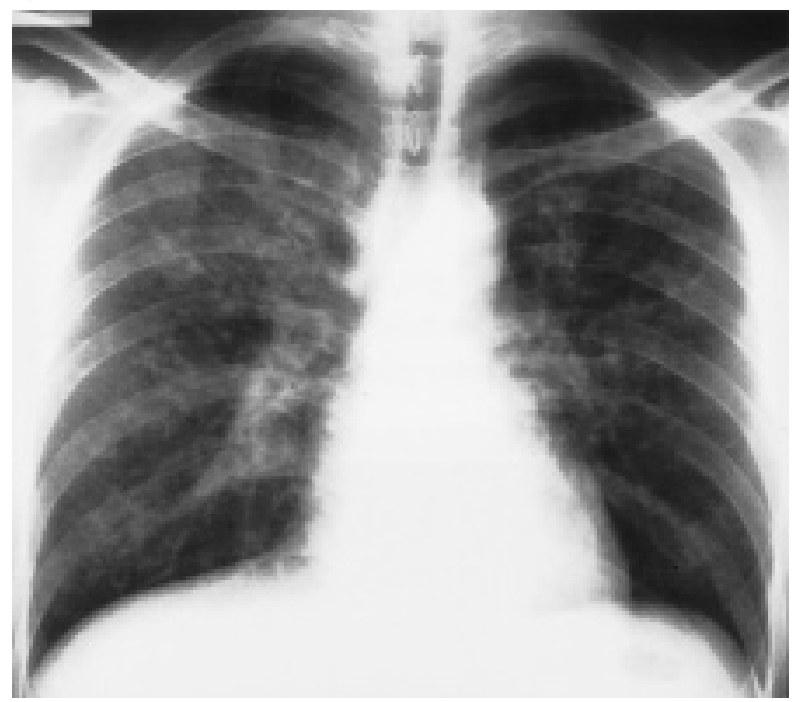

b)

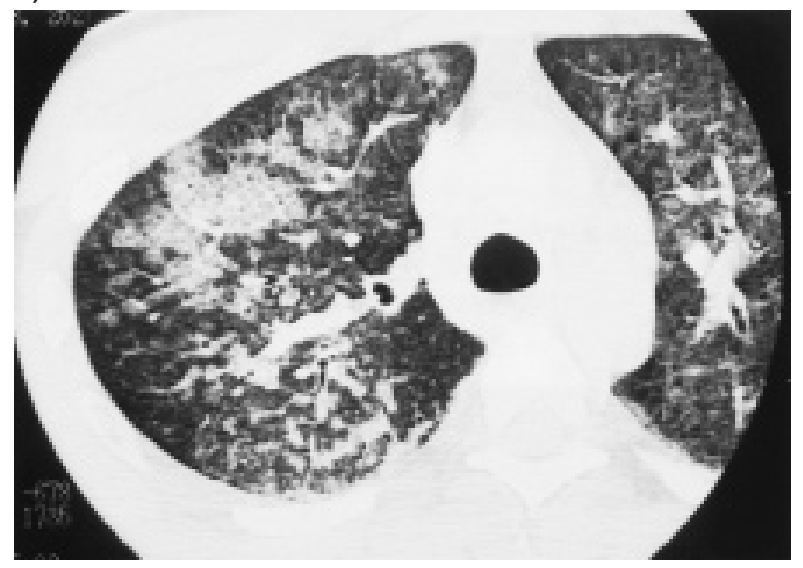

Fig. 1. - Radiological examinations of the lung. a) a chest radiograph on day 4 demonstrating diffuse reticulonodular infiltrates of bilateral lungs. b) chest high resolution computed tomogram on day 4 revealing diffuse ground-glass opacities, multiple centrilobular nodules, and consolidations predominant in the right upper lobe.

Lung tissue obtained by transbronchial biopsy showed well-conserved alveolar structure, with alveoli lined by prominent type II alveolar pneumocytes, and the presence of a large number of macrophages within the small airspaces (not shown). Giant cells were not detected in the affected area. Sputum culture was negative for other bacterial, or fungal pathogens. Serological tests demonstrated positive IgM as well as IgG antibodies against measles virus. He was treated with oxygen, roxithromycin for possible superimposed bacterial infection followed by intravenous infusion of $\gamma$-globulin containing high-titre antibodies to measles virus. His respiratory status improved on hospital day 9, and he was discharged from the hospital on day 14 with his physical condition as well as laboratory data fully normalized.

Detection of measles virus using RT-PCR technique in lung cells recovered by $B A L$

Ten millilitres of the fluid recovered by BAL was centrifuged at $870 \times g$ for $10 \mathrm{~min}$ at $4^{\circ} \mathrm{C}$, and supernatant and cellular components were collected separately. First, cellular components were washed twice with phosphatebuffered saline, resuspended in Dulbecco's modified Eagle medium and incubated for $1 \mathrm{~h}$ at $37^{\circ} \mathrm{C}$ in $10 \% \mathrm{CO}_{2}$. These cells were divided into adherent (mainly macrophages) and nonadherent (lymphocyte-rich) cell fractions [8]. Total RNA was extracted from the culture supernatant, adherent cells, nonadherent cells, as well as the patient's serum using the guanidinium iso-thiocyanate- $\mathrm{CsCl}_{2}$ ultracentrifugation method or the acid guanidinium thiocyanate phenol-chloroform extraction method [9, 10]. Resultant RNA was dissolved in $10 \mu \mathrm{L}$ of ribonuclease (RNase)free distilled water. The initial transcription of RNA to complementary deoxyribonucleic acid (cDNA) was performed by using Moloney murine leukaemia virus reverse transcriptase with random hexamer primers [11]. Twostep amplification (semi-nested PCR) was carried out to detect the matrix gene of measles viral genome with the primer pairs as described by SHIMIZU et al. [12]; 5'GTGTTGTTTATATGAGCATCAC-3' (MV03) and 5'AATCGATTAAGGTCTTCATTGAT-3' (MV05) as outer primers, and for the second semi-nested PCR, an inner antisense primer MV04 (5'-CATTTTGCAATAATCGGCAGAGT-3') was used instead of MV05 [13]. The reaction conditions were first $94^{\circ} \mathrm{C}$ for $3 \mathrm{~min}$, and them $94^{\circ} \mathrm{C}$ for $1 \mathrm{~min}, 60^{\circ} \mathrm{C}$ for $1 \mathrm{~min}$, and $72^{\circ} \mathrm{C}$ for $1 \mathrm{~min}$, which were repeated for 40 cycles. A single PCR product
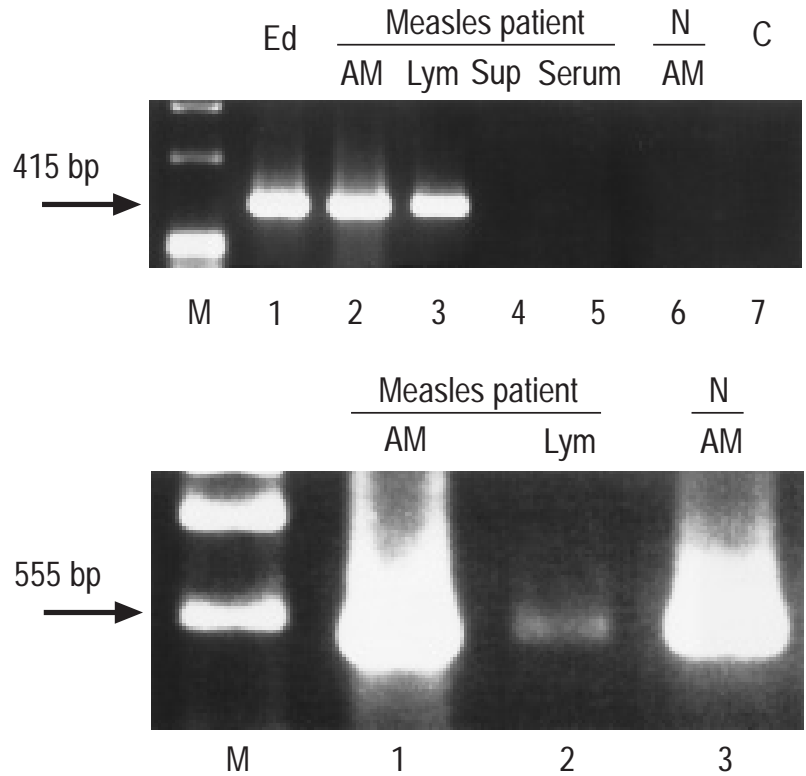

Fig. 2. - Detection of the measles virus genome in lung cells from the individual with measles pneumonia by reverse transcription-polymerase chain reaction (RT-PCR) amplification. a) first-round PCR amplification showing the presence of measles virus in lung cells recovered by bronchoalveolar lavage (BAL) but not in lavage supernatant or serum of the patient. M, molecular marker (ФX174/HaeIII); lane 1, ribonucleic acid (RNA) extracted from Edmonston's measles virus strain (Ed) as positive control [20]; lanes 2-5, alveolar macrophages (AM), lymphocytes (Lym), supernatant (Sup) recovered by BAL, and serum from the measles patient, respectively; lane 6, AM from a healthy volunteer $(\mathrm{N})$; lane 7 , negative control with no complementary deoxyribonucleic acid (cDNA) (C). b) RT-PCR amplification of glyceraldehyde-3-phosphate dehydrogenase (GAPDH) cDNA as control: $\mathrm{M}$, molecular marker as in a); lanes 1 and 2, AM, and Lym from the measles patient, respectively; lane 3 , AM from the healthy individual. Both gels contained $2 \%$ agarose and were stained with ethidium bromide for visualization. Sizes of PCRamplification products are indicated. 
of the predicted size (415 base pairs (bp)) was readily demonstrated in cDNA samples from alveolar macrophages and lymphocytes, but not from BAL supernatant or serum of the indicated case (fig. 2a). The measles viral genome was not detected from alveolar macrophages from a "normal" individual. The semi-nested PCR amplification further confirmed the presence of measles genome in alveolar macrophages and lymphocytes as evidenced by presence of a $251 \mathrm{bp}$ band, but not in BAL supernatant or serum of the patient with measles pneumonia (not shown). As a control, glyceraldehyde-3-phosphate dehydrogenase (GAPDH) messenger (m)RNA (cDNA) was detected by PCR-amplification in all the RNA samples extracted from lung cells of the indicated case and the healthy control (fig. 2b) $[15]$.

\section{Discussion}

This report describes an adult case of measles pneumonia presented with typical clinical features of measles and developed respiratory failures. Although the diagnosis of measles was also confirmed serologically, it took $>2$ weeks. Additionally, pneumonia complicated with measles may become severe in immunodeficient individuals [3]. However, it is not easy to make a precise diagnosis because these individuals often lack typical clinical features of measles or exhibit defects in antigen-specific antibody production [16]. Therefore, it is of importance to rapidly determine the pathogenesis of pneumonia by using the molecular microbiology techniques such as RT-PCR for detection of measles virus within lavaged lung cells. Compared to the conventional laboratory techniques such as detection of serum antibody titre against measles virus or immunohistochemical confirmation of the virus in tissues, the method we utilized may require a shorter time and fewer technical procedures to obtain proof of measles infection.

Measles virus still remains one of the major causes of serious infectious diseases with high mortality in developing countries [3, 17]. Additionally, there were outbreaks of measles at the end of the 1980s and also in 1990 in the USA [18]. Lower respiratory tract complications develop in $4-50 \%$ of these patients, and it is believed to be much more common in developing countries [3]. It has also been reported that the fatality of measles is higher in patients with pneumonia than those without it [4]. Vitamin A therapy may reduce morbidity and mortality in severe measles in children, and was also effective in an adult case of measles pneumonia $[5,6]$. In this context, it is important not only to detect the pathogen of pneumonia in the very early stages, but also to initiate adequate treatment immediately.

The localization of measles virus in the lung has been analysed by the immunoperoxidase method using monoclonal antibodies and by electron microscopic analysis [7, 19]. Measles virus tends to reside in giant cells and in type II alveolar epithelium in the lung. It has also been isolated from peripheral blood lymphocytes, monocytes, neutrophils, platelets and serum itself [20]. Other reports have shown the measles virus genome to be detectable in nasal secretions and throat swab by reverse transcriptionpolymerase chain reaction amplification, and these me- thods provided highly sensitive and specific modalities [12]. However, little is known about whether measles virus may infect the other cells in the lung, such as alveolar macrophages, or lymphocytes. Our data presented in this report clearly demonstrate that the measles virus infected not only alveolar macrophages but also lymphocytes in the lung, even though the viral genome was not found in serum in the initial stage of pneumonia. However, since it remains unclear whether measles virus is normally absent in lung cells in healthy individuals, more detailed investigation may be needed.

\begin{abstract}
Acknowledgements. The authors thank A. Hagiwara of the Dept of Virology II, National Institute of Health, Tokyo, Japan, for the kind gift of the original measles virus isolate (Edmonston's strain), and T. Ohashi and Y. Eto of the Dept of Gene Therapy, Institute of DNA Medicine, The Jikei University School of Medicine, Tokyo, Japan for their helpful discussion.
\end{abstract}

\section{References}

1. Gustafson TL, Lievens AW, Brunell PA, Moellenberg RG, Buttery CMG, Sehulster LM. Measles outbreak in a fully immunized secondary-school population. $N$ Engl $J$ Med 1987; 320: 771-774.

2. Griffin DE, Ward BJ, Esolen LM. Pathogenesis of measles virus infection: an hypothesis for altered immune responses. J Infect Dis 1994; 170 (Suppl. 1): S25S31.

3. Murray JF, Nadel JA. Textbook of Respiratory Medicine. 2nd Ed. Philadelphia, PA, USA, WB Saunders Company, 1994; pp. 1007-1009.

4. Swift JD, Barruga MC, Perkin RM, Stralen DV. Respiratory failure complicating rubeola. Chest 1993; 104: 1786-1787.

5. Fawzi WW, Chalmers TC, Herraa MG, Herrera MG, Mosteller F. Vitamin A supplementation and child mortality. JAMA 1993; 269: 898-903.

6. Rupp ME, Schwartz ML, Bechard DE. Measles pneumonia: treatment of a near-fatal case with corticosteroids and vitamin A. Chest 1993; 103: 1625-1626.

7. Sata T, Kurata T, Aoyama Y, Sakaguchi M, Yamanouchi $\mathrm{K}$, Takeda K. Analysis of viral antigens in giant cells of measles Pneumonia by immunoperoxidase method. Virchows Arch A 1986; 410: 133-138.

8. Spiteri MA, Clarke SW, Poulter LW. Isolation of phenotypically and fimctionally distinct macrophage subpopulations from human bronchoalveolar lavage. Eur Respir J 1992; 5: 717-726.

9. Chargwin JM, Przybyla AE, MacDonald RJ, Rutter WJ. Isolation of biologically active ribonucleic acid from sources enriched in ribonuclease. Biochemistry 1979; 18: 5294-5299.

10. Chomczynski P, Sacchi N. Single-step method of RNA isolation by acid guanidinium thiocyanate-phenol-chloroform extraction. Anal Biochem 1987; 162: 156-159.

11. Roth MJ, Tanese N, Goff SP. Purification and characterization of murine retroviral reverse transcriptase expressed in Escherichia coli. J Biol Chem 1985; 260: 9326-9335. 
12. Shimizu H, McCarthy CA, Smaron MF, Burns JC. Polymerase chain reaction for detection of measles virus in clinical samples. J Clin Microbiol 1993; 31: 1034-1039.

13. Saiki RK, Gelfand DH, Stoffel S, et al. Primer-directed enzymatic amplification of DNA with a thermostable DNA polymerase. Science 1988; 239: 487-491.

14. Enders JF, Peebles TC. Propagation in tissue cultures of cytopathic agents from patients with measles. Proc Soc Exp Biol Med 1954; 86: 277-286.

15. Tso JY, Sun XH, Kao T, Reece KS, Wu R. Isolation and characterization of rat and human glyceraldehyde-3-phosphate dehydrogenase cDNAs: genomic complexity and molecular evolution of the gene. Nucleic Acids Res 1985; 13: 2485-2502.

16. Kaplan LJ, Daum RS, Smaron M, McCarthy CA. Severe measles in immunocompromised patients. JAMA 1992; 267: 1237-1241.

17. Cutts FT, Markowitz LE. Successes and failures in measles control. J Infect Dis 1994; 170 (Suppl. 1): S32S41.

18. Hutchins S, Markowitz L, Atkinson W, Swint E, Hadler S. Measles outbreaks in the United States, 1987 through 1990. Pediatr Infect Dis J 1996; 15: 31-38.

19. Rahman SM, Eto H, Morshed SA, Itakura H. Giant cell pneumonia: light microscopy, immunohistochemical, and ultrastructural study of an autopsy case. Ultrastr Pathol 1996; 20: 585-591.

20. Shiraishi H. Virological studies of the virus shedding pattern of natural measles. Kansenshogaku-Zasshi (in Japanese) 1990; 64: 1305-1311. 